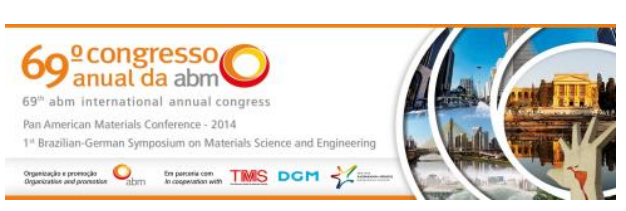

Tema: Iniciação Científico-tecnológica

\title{
CARACTERIZAÇÃO DE REVESTIMENTOS DE NÍQUEL OBTIDOS POR ASPERSÃO TÉRMICA HVOF NO AÇO API 5CT P110*
}

\section{Resumo}

\author{
Leandro Brunholi Ramos ${ }^{1}$ \\ Cristiane de Souza Brandolt ${ }^{2}$ \\ Antonio Shigueaki Takimi ${ }^{3}$ \\ Roberto Moreira Schroeder ${ }^{4}$ \\ Célia de Fraga Malfatti ${ }^{5}$
}

O aço API 5 CT P110 é amplamente utilizado no setor de petróleo e gás no Brasil devido sua elevada resistência mecânica, contudo ele não possui uma boa resistência a corrosão. Com a descoberta do pré-sal, novos desafios surgem neste setor, tornando necessário o desenvolvimento de novas tecnologias resistentes aos ambientes agressivos que os materiais serão expostos. A aspersão térmica por HVOF se destaca pela obtenção de revestimentos contra corrosão e resistentes ao desgaste com baixa porosidade e com um relativo baixo custo em comparação a outros processos. Dentre os materiais que podem ser aplicados como revestimentos por aspersão térmica, o níquel se destaca pela ótima resistência à corrosão por formar um óxido protetor na superfície. Sendo assim, o presente trabalho tem por objetivo obter e caracterizar revestimentos de níquel obtidos por aspersão térmica HVOF, no aço API 5CT P110. Os revestimentos foram caracterizados morfologicamente por microscopia eletrônica de varredura (MEV). Foram obtidas curvas de polarização para avaliar o comportamento frente à corrosão e foram realizados ensaios para determinação do coeficiente de atrito. A camada aspergida de níquel apresentou resultados satisfatórios quanto às análises estudadas. Palavras-chave: Aspersão térmica HVOF; Corrosão; MEV e coeficiente de atrito.

\section{CHARACTERIZED NICKEL COATINGS OBTAINED BY THERMAL SPRAY HVOF IN API 5CT P110 STEEL}

\section{Abstract}

The API 5 CT P110 steel has been utilized in oil and gas sector in Brazil due to its high mechanic resistance, but it has low corrosion resistance. The discovery pre-salt has been encouraged news challenges in this sector and the development the news technologies resists to harsh environments where the materials are going to exposed. The thermal spray by HVOF stands out for making coatings against corrosion and wear resistance with few pores and cheaper than others process. Among the materials that can be making the coatings for thermal spray, the nickel stands out for excellent corrosion resistance because do a protector oxide on the surface. So, the main object this work is get and characterize nickel coatings made for thermal spray HVOF in API 5 CT P110 steel. The coatings were morphologic characterized for scanning electron microscope (SEM). Polarization plots were realized to study behavior corrosion and were realized tests to define the friction coefficient. The nickel coating had behavior satisfactory in this study.

Keywords: Thermal spray HVOF; Corrosion; SEM and friction coefficient.

1 Estudante de Engenharia Metalúrgica, Universidade Federal do Rio Grande do Sul (UFRGS), Porto Alegre, RS, Brasil.

2 Mestre em Engenharia, UFRGS, Porto Alegre, RS, Brasil.

3 Professor Doutor, Universidade Federal de Pelotas, Pelotas, RS, Brasil.

Doutor em Engenharia, UFRGS, Porto Alegre, RS, Brasil.

5 Professora Doutora, UFRGS, Porto Alegre, RS, Brasil.

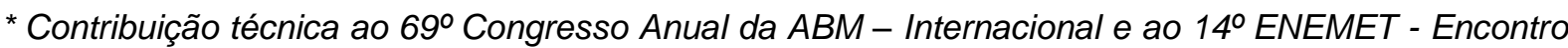
Nacional de Estudantes de Engenharia Metalúrgica, de Materiais e de Minas, 21 a 25 de julho de 2014, São Paulo, SP, Brasil.
} 


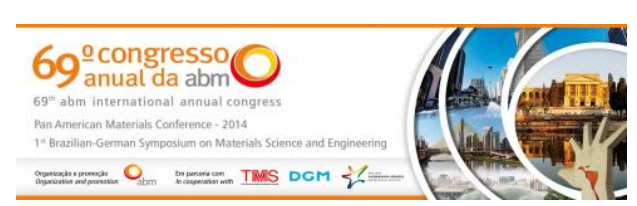

\section{INTRODUÇÃO}

Com o pré-sal, a produção de petróleo no Brasil crescerá significativamente. Contudo, devido às condições de exploração do petróleo nessas áreas, como o próprio ambiente, que é agressivo, buscam-se novas tecnologias e materiais mais resistentes à corrosão. O aço API 5CT P110 é utilizado no setor de petróleo e gás como tubo de revestimento de poços de petróleo devido sua alta resistência, boa tenacidade e ser baixa liga, além de boa soldabilidade. [1, 2]

Uma técnica já utilizada pela indústria do petróleo e gás para proteção contra corrosão e para aumentar a resistência ao desgaste é a aspersão térmica, que tem por objetivo a obtenção de um revestimento protetor. Nessa técnica de recobrimento, o material que será utilizado como revestimento, na forma de pó, é fundido e projetado contra a superfície do material. Ao se chocarem contra o substrato, estas partículas se achatam na forma de pequenas lentes; ao se resfriarem rapidamente, elas se aderem a superfície, formando uma estrutura lamelar de partículas achatadas em direção paralela a superfície do substrato, contendo, também, impurezas e defeitos, como mostra a figura 1 [3, 4].

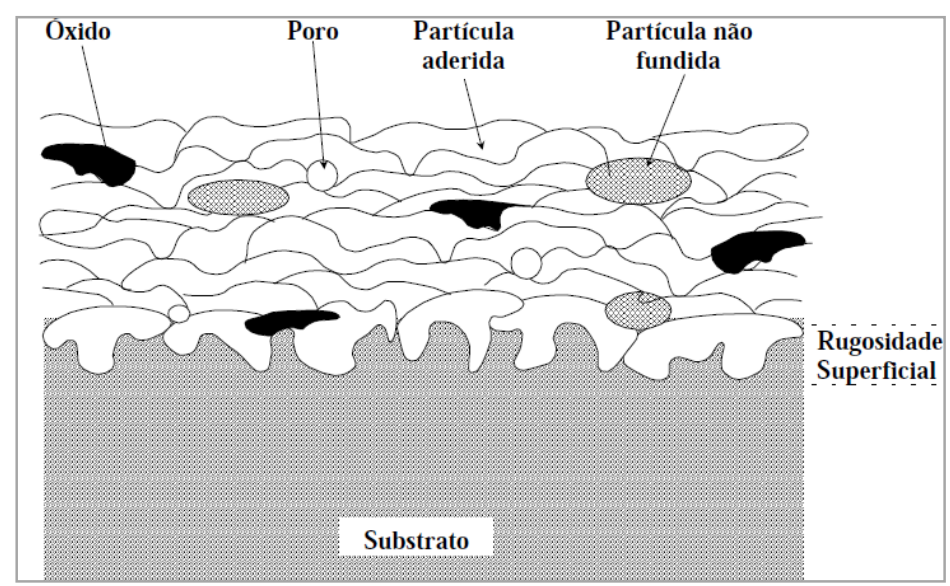

Figura 1. Formação de um recobrimento por aspersão térmica [4]

Dentre as técnicas de revestimento por aspersão térmica, se destaca a do tipo por chama hipersônica, HVOF (High Velocity Oxygem Fuel), por apresentar revestimentos de baixa porosidade e elevada aderência, que são características necessárias para se opor à corrosão e à resistência ao desgaste [5].

Neste processo ocorre uma reação entre um combustível e o oxigênio, em uma câmera. A combustão, que é iniciada por um sistema de ignição, libera energia que é convertida em calor e pressão aquecendo e impulsionando as partículas de pó, formando um jato de chama. As partículas atingem velocidade hipersônicas, formando um revestimento com poucos poros e elevada adesão [6].

Para se ter um revestimento barreira contra corrosão, o material que será aspergido, deve ter baixo ponto de fusão, em relação a temperatura da chama, para que haja fusão suficiente das partículas metálicas a ponto que o revestimento fique coeso e compacto. O níquel, além de apresentar baixo ponto de fusão - comparando com as temperaturas do processo- apresenta boa resistência a corrosão. Baseado nessas características, escolheu-se o níquel, por parecer apresentar propriedades adequadas para ser aplicado como revestimento por aspersão térmica nos aços API 5CT P110, atendendo, a priori, os objetivos desse trabalho.

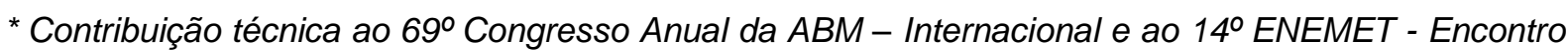
Nacional de Estudantes de Engenharia Metalúrgica, de Materiais e de Minas, 21 a 25 de julho de 2014, São Paulo, SP, Brasil.
} 


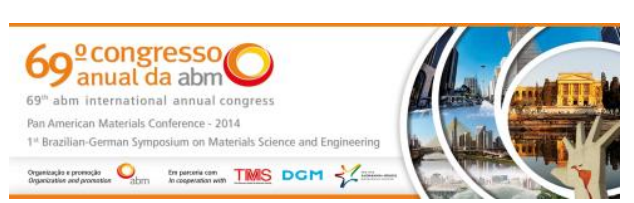

Desta forma, no presente trabalho foi aplicado o revestimento de níquel pela técnica de aspersão tipo HVOF no substrato de aço API 5CT P110, e caracterizado com relação a porosidade, morfologia, resistência à corrosão e ao coeficiente de atrito.

\section{MATERIAIS E MÉTODOS}

\subsection{Substrato}

O material base é o aço API 5CT P110, fornecido pela PETROBRAS em forma de tubo com diâmetro de $170 \mathrm{~mm}$ e espessura de $12,7 \mathrm{~mm}$. Foi realizada análise química através de um espectrômetro de emissão ótica modelo Spectrolab tipo LAVFA 18B, da Spectro. O aparelho é calibrado com padrões espectro de acordo com a norma DIN ISO 100012.1.

O tubo foi cortado e usinado nas seguintes dimensões: $90 \mathrm{~mm}$ x $14 \mathrm{~mm}$ x $8 \mathrm{~mm}$. Conforme figura 2:

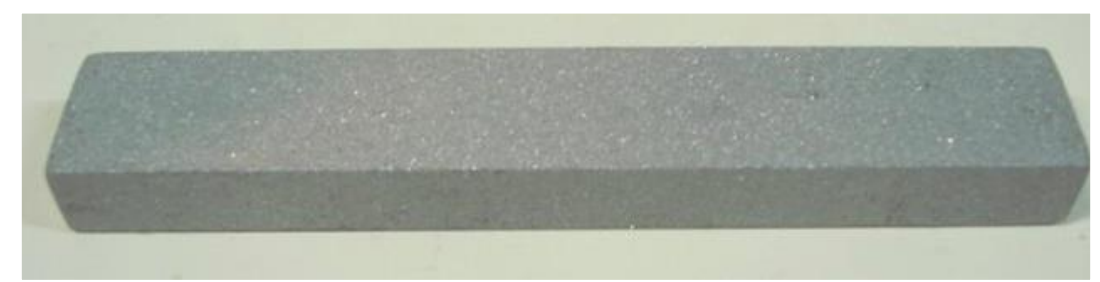

Figura 2. Corpo de prova retangular de aço API 5CT P110 utilizado nos ensaios.

\subsection{Revestimento}

O revestimento foi obtido utilizando pó de níquel com pureza 99,9425\%, como informado pelo fornecedor; a densidade do mesmo é de $3,8 \mathrm{~g} / \mathrm{cm}^{3}$.

\subsection{Aspersão térmica}

Para o processo de aspersão térmica foi utilizado um equipamento TAFA JP 5000 HP/HVOF System Modelo 5120, da fabricante PRAXAIR e uma pistola TAFA GUN Model 5220. Os revestimentos foram obtidos na Rijeza Indústria Metalúrgica LTDA, situada no município de São Leopoldo-RS. As amostras de aço passaram por um pré-tratamento antes da aspersão térmica, conforme Figura 3.

\footnotetext{
* Contribuição técnica ao 69ำ Congresso Anual da ABM - Internacional e ao 14ํㅡㄹ ENEMET - Encontro Nacional de Estudantes de Engenharia Metalúrgica, de Materiais e de Minas, 21 a 25 de julho de 2014, São Paulo, SP, Brasil.
} 


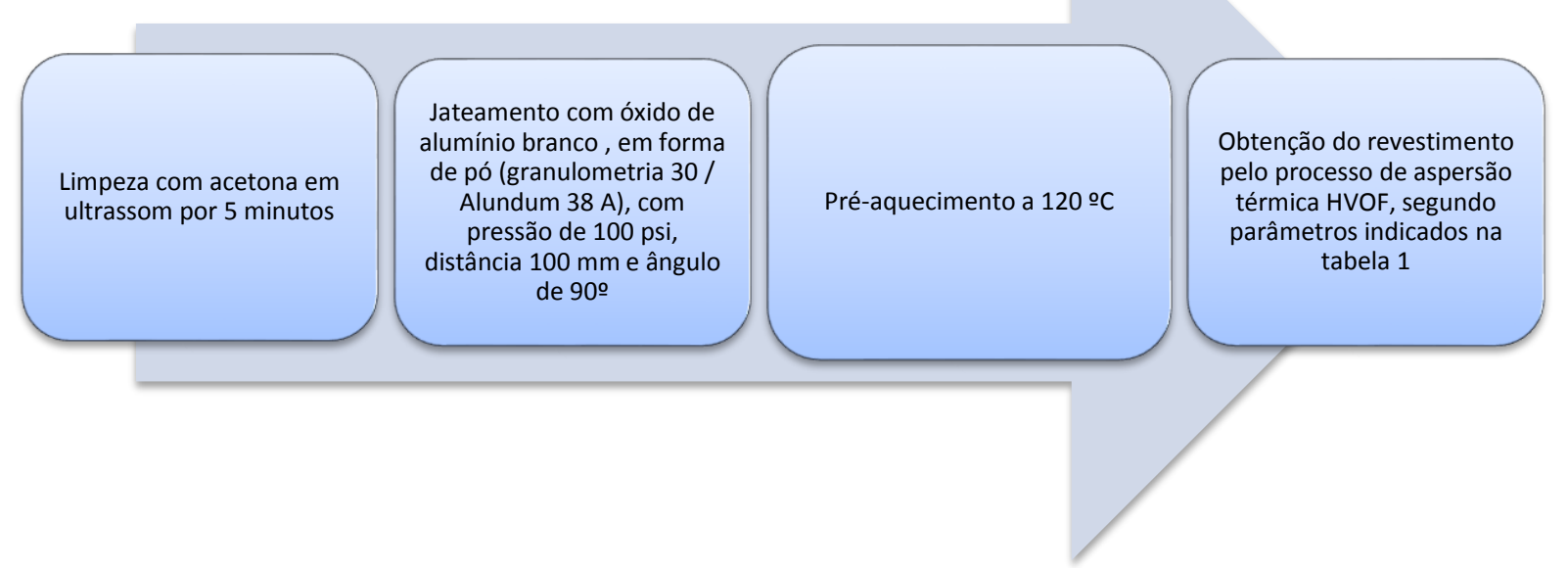

Figura 3. Fluxograma do pré-tratamento realizado nas amostras para a obtenção do revestimento de níquel por aspersão térmica tipo HVOF.

Os parâmetros de aspersão térmica utilizados na obtenção do revestimento de níquel segue conforme Tabela 1.

Tabela 1. Parâmetros de aspersão térmica utilizados na obtenção dos revestimentos de níquel.

\begin{tabular}{|l|l|}
\hline Taxa de alimentação & $76 \mathrm{~g} / \mathrm{min}$ \\
\hline Canhão & $6 "$ \\
\hline Pressão de oxigênio & $140+/-5 \mathrm{psi}$ \\
\hline Vazão de oxigênio & $2055 \mathrm{scfh}$ \\
\hline Pressão de combustível & $133+/-5 \mathrm{psi}$ \\
\hline Vazão de combustível & $5,2 \mathrm{gph}$ \\
\hline Pressão de nitrogênio - gás de arraste & $50 \mathrm{psi}$ \\
\hline Vazão de nitrogênio - gás de arraste & $10+/-1 \mathrm{scfh}$ \\
\hline Pressão de ar comprimido & $116 \mathrm{psi}$ \\
\hline Velocidade do disco alimentador & $5,5 \mathrm{rpm}$ \\
\hline Distância da pistola & $300 \mathrm{~mm}$ \\
\hline Inclinação da pistola & $0^{\circ}$ \\
\hline Velocidade de deslocamento da pistola & $19000 \mathrm{~mm} / \mathrm{s}$ \\
\hline Distância entre passes & $5 \mathrm{~mm}$ \\
\hline Camada esperada & $0,2 \mathrm{~mm}$ \\
\hline Número de Passes & 4 \\
\hline
\end{tabular}

\subsection{Microscopia Eletrônica de Varredura}

Para análise morfológica do revestimento foi utilizado Microscopia Eletrônica de Varredura (MEV), no Centro de Microscopia Eletrônica da UFRGS (CEM - UFRGS).

\footnotetext{
* Contribuição técnica ao $69^{\circ}$ Congresso Anual da ABM - Internacional e ao 14ํㅡㄹ ENEMET - Encontro Nacional de Estudantes de Engenharia Metalúrgica, de Materiais e de Minas, 21 a 25 de julho de 2014, São Paulo, SP, Brasil.
} 


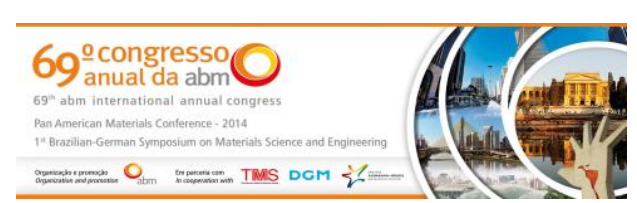

Utilizou-se um microscópio JEOL 5800 acoplado a um equipamento de análise dispersiva de raios-X (EDS), marca Noran com sistema computacional de aquisição de imagens. As amostras foram observadas em vista de topo para identificação da morfologia superficial e também em corte transversal.

\subsection{Polarização Potenciodinâmica}

Os ensaios eletroquímicos foram realizados através dos ensaios de polarização potenciodinâmica em um potenciostato/galvanostato AUTOLAB no Laboratório de Pesquisa em Corrosão da UFRGS (LAPEC - UFRGS), exibido na Figura 4 e na Figura 5. Na imagem é possível observar o computador para aquisição dos dados que é acoplado ao equipamento, e uma gaiola de Faraday, para diminuição de interferências ao sistema, onde é alojada a célula eletroquímica.

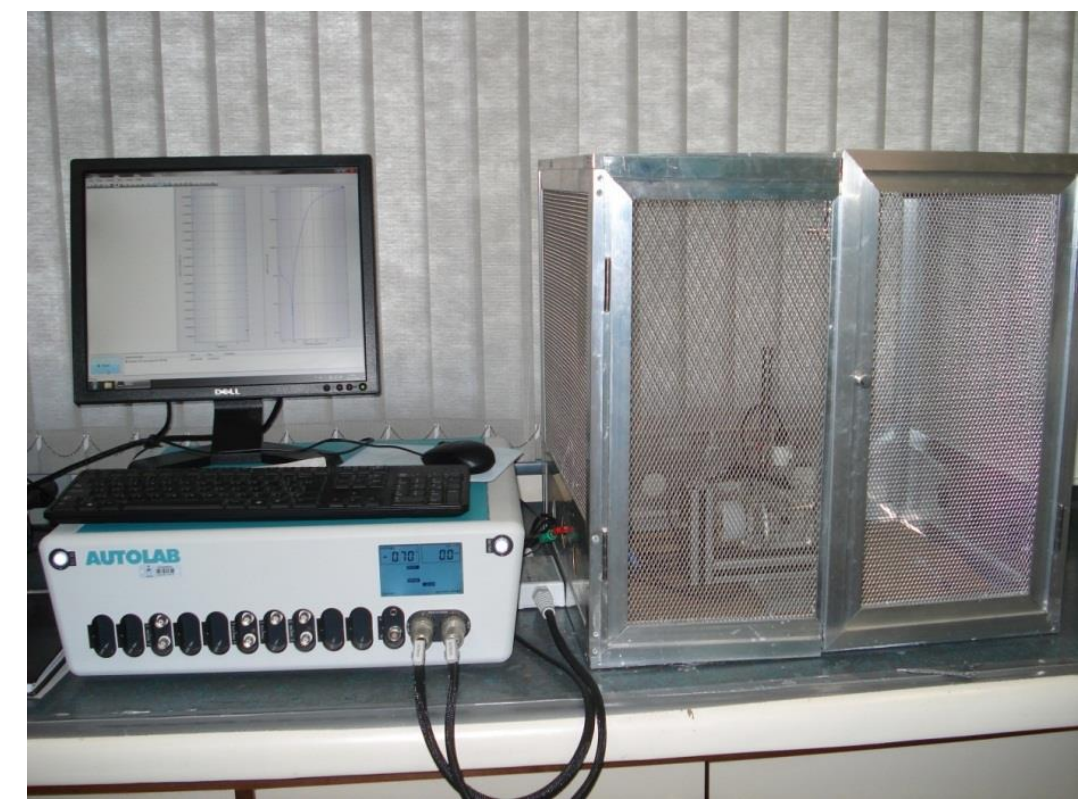

Figura 4. Equipamento potenciostato/galvanostato AUTOLAB utilizado nos ensaios eletroquímicos acoplado a computador para processamento dos dados e gaiola de Faraday.

\footnotetext{
* Contribuição técnica ao $69^{\circ}$ Congresso Anual da ABM - Internacional e ao 14ํㅡㄹ ENEMET - Encontro Nacional de Estudantes de Engenharia Metalúrgica, de Materiais e de Minas, 21 a 25 de julho de 2014, São Paulo, SP, Brasil.
} 

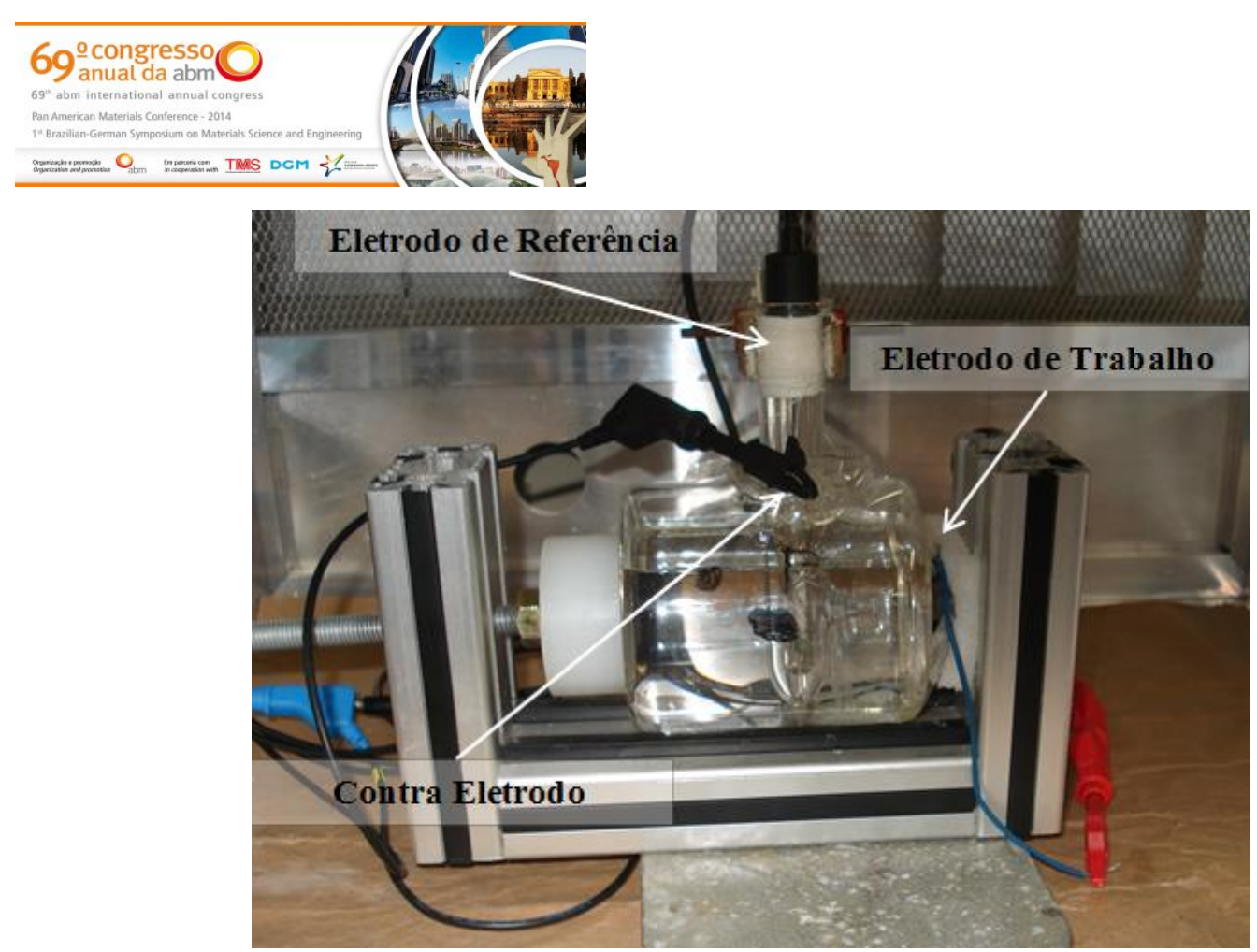

Figura 5. Célula de três eletrodos empregada nos ensaios eletroquímicos.

As medidas foram realizadas em meio não agitado, naturalmente aerado e à temperatura ambiente, com concentração do eletrólito de $\mathrm{NaCl}$ de $0,5 \mathrm{M}$. Na polarização potenciodinâmica, o intervalo de varredura foi de $-200 \mathrm{mV}$ abaixo do potencial de circuito aberto até $1000 \mathrm{mV}$, com velocidade de varredura de $1 \mathrm{mV} . \mathrm{s}-1$. Os dados obtidos das medidas de polarização potenciodinâmica foram tratados com o software Nova para a obtenção do potencial de corrosão (Ecorr),e da densidade de corrente de corrosão (icorr).

\subsection{Determinação do Coeficiente de Atrito}

Para a determinação do coeficiente de atrito, foram realizados ensaios de desgaste a seco na amostra de aço revestido com níquel e na amostra de aço. O principal objetivo foi avaliar qual dos materiais apresentou maior coeficiente de atrito. Os ensaios foram realizados em um tribômetro da fabricante CETR, conforme Figura 6, onde foram realizadas trilhas de desgaste, e obtidos valores de coeficiente de atrito pelo tempo.

Os parâmetros utilizados nos ensaios para a determinação do coeficiente de atrito foram:

- Esfera: Alumina (cerâmica) de 4,76mm de diâmetro;

- Força Normal aplicada: 3N;

- Frequência: 3Hz;

- Tamanho da Trilha: 2mm;

- Tempo de desgaste: 20min;

\footnotetext{
* Contribuição técnica ao $69^{\circ}$ Congresso Anual da ABM - Internacional e ao 14ํㅡㄹ ENEMET - Encontro Nacional de Estudantes de Engenharia Metalúrgica, de Materiais e de Minas, 21 a 25 de julho de 2014, São Paulo, SP, Brasil.
} 


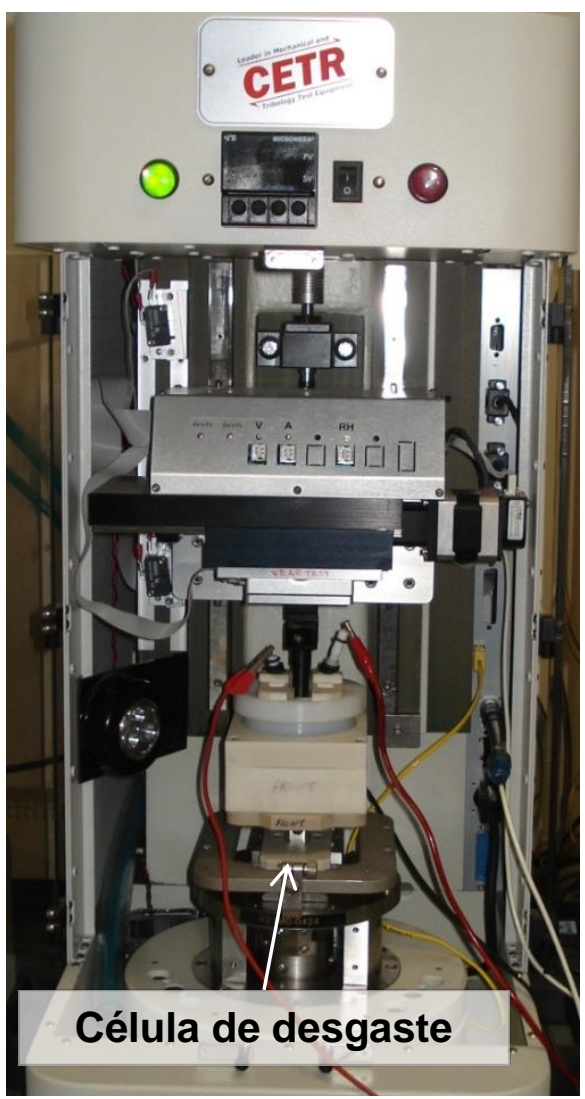

Figura 6. Tribômetro utilizado nos ensaios para determinação do coeficiente de atrito.

\section{RESULTADOS E DISCUSSÃO}

\subsection{Substrato}

O aço API 5CT P110 foi analisado por espectroscopia de emissão ótica, que obteve sua composição química, como mostra a Tabela 2.

Tabela 2. Composição química do material estudado obtida por espectrometria de emissão óptica.

\begin{tabular}{|l|l|l|l|l|l|l|l|}
\hline $\begin{array}{l}\text { (\%) máx } \\
\text { API }\end{array}$ CCT & C & Mn & P & S & Cr & Mo & Ni \\
\cline { 2 - 8 } & 0,30 & 0,65 & 0,02 & 0,01 & 1,01 & 0,20 & 0,17 \\
\hline
\end{tabular}

\subsection{Revestimento}

A Tabela 3 mostra os valores de diâmetro 10\%, 50\%, 90\% e o diâmetro médio do pó de níquel.

Tabela 3. Tabela com resultados de distribuição do pó de Ni.

\begin{tabular}{|l|l|}
\hline & Níquel \\
\hline Diâmetro a $10 \%$ & $10,69 \mu \mathrm{m}$ \\
\hline Diâmetro a $50 \%$ & $27,04 \mu \mathrm{m}$ \\
\hline Diâmetro a $90 \%$ & $44,02 \mu \mathrm{m}$ \\
\hline Diâmetro médio & $27,25 \mu \mathrm{m}$ \\
\hline
\end{tabular}

\footnotetext{
* Contribuição técnica ao $69^{\circ}$ Congresso Anual da ABM - Internacional e ao 14ํㅡㄹ ENEMET - Encontro Nacional de Estudantes de Engenharia Metalúrgica, de Materiais e de Minas, 21 a 25 de julho de 2014, São Paulo, SP, Brasil.
} 


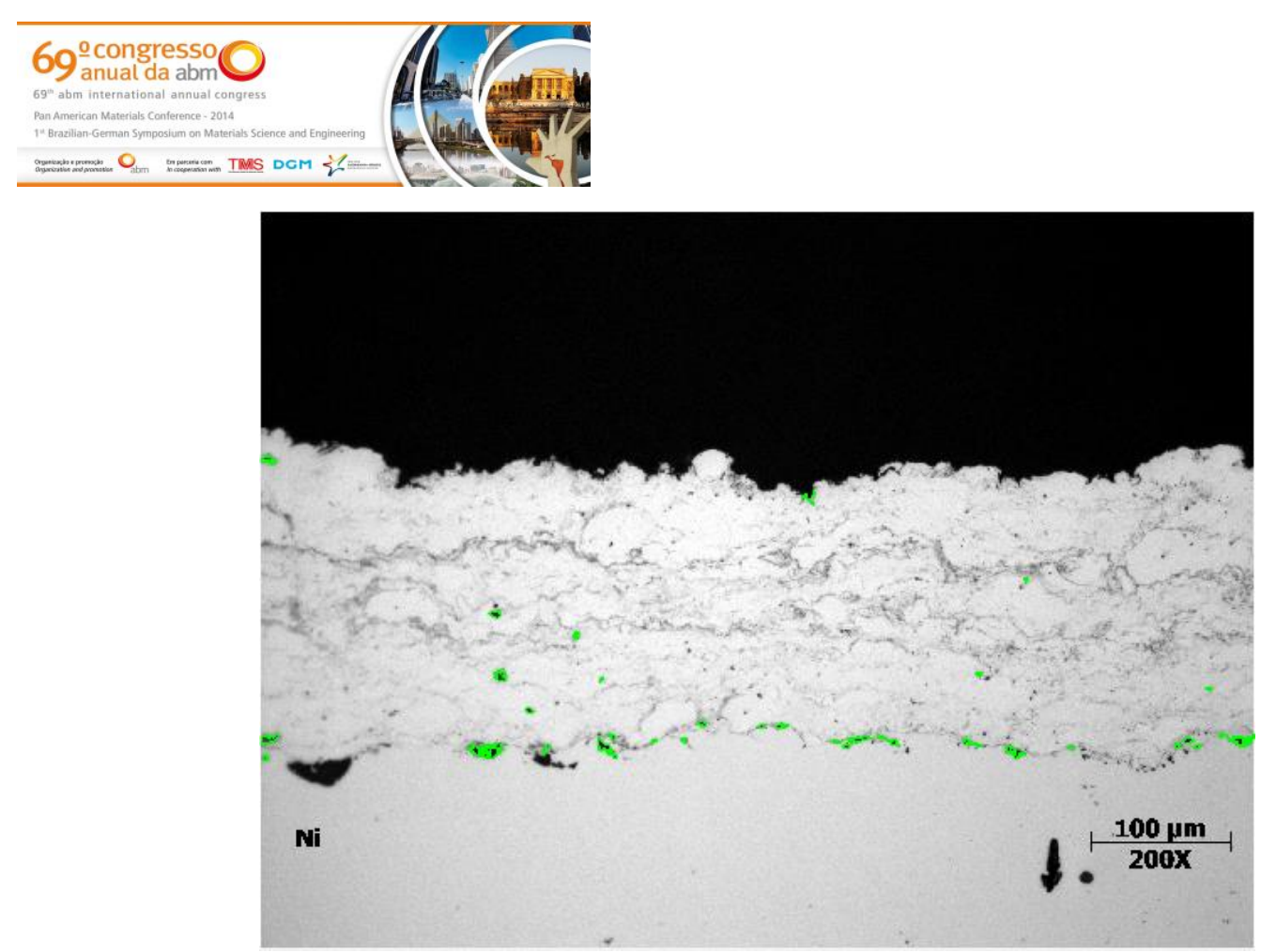

Figura 8. Revestimento de níquel com regiões de porosidade em coloração verde.

A Figura 9 mostra a imagem de topo do revestimento de níquel obtidas por microscopia eletrônica de varredura. Observa-se que o revestimentos possui irregularidade em sua morfologia. Também pode-se observar que, aparentemente, há poros superficiais. Entretanto, não há indícios de trinca e/ou microtrincas.

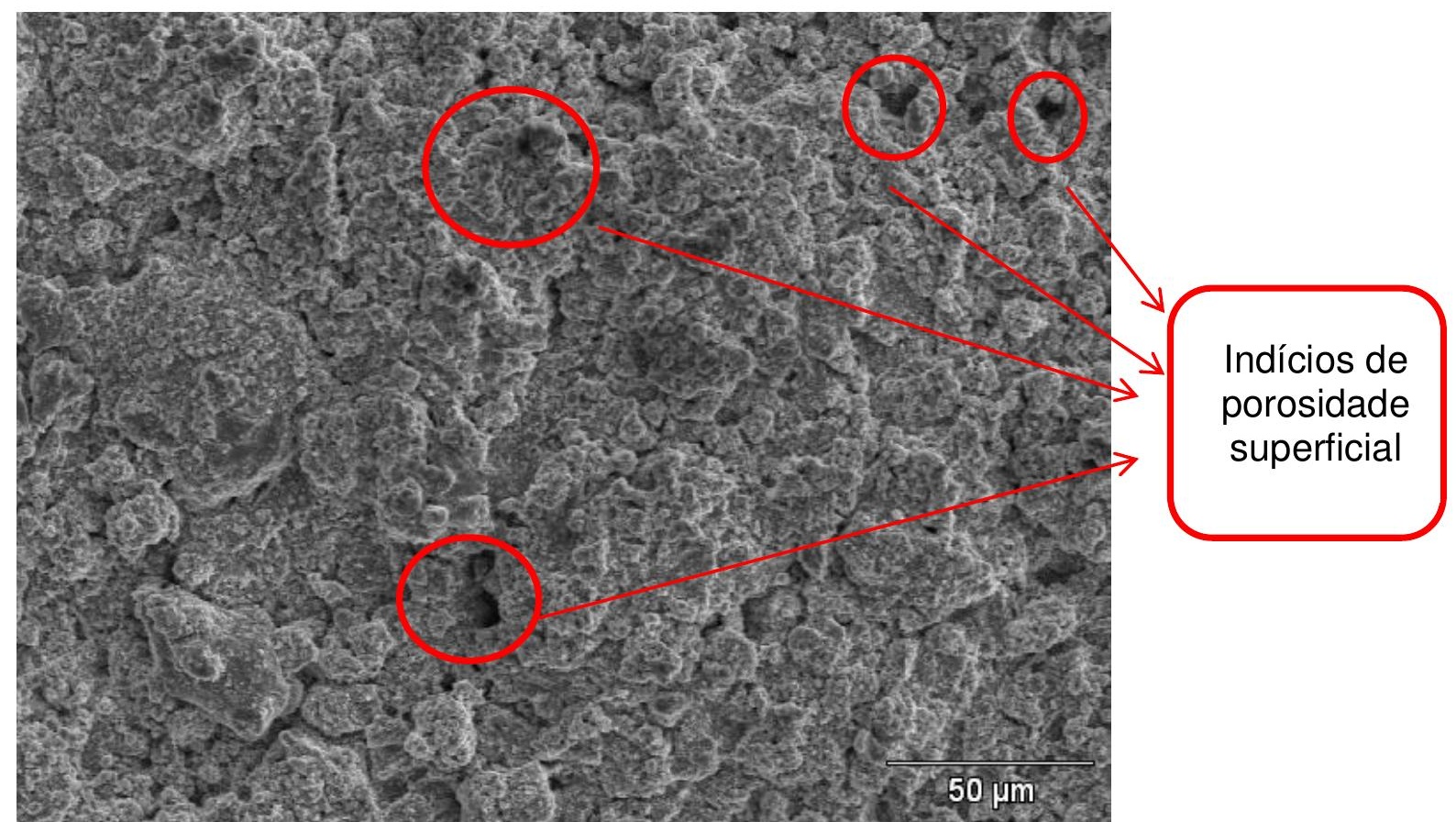

Figura 9. Imagem de topo do revestimento de níquel obtida por microscopia eletrônica de varredura.

Já a Figura 10 mostra a seção transversal do revestimento de níquel obtida por microscopia eletrônica de varredura. Nota-se que o revestimento não apresenta regiões porosas, nem trincas e/ou microtrincas ao longo dessa seção do revestimento.

\footnotetext{
* Contribuição técnica ao 69 Congresso Anual da ABM - Internacional e ao 14ํㅡㄹ ENEMET - Encontro Nacional de Estudantes de Engenharia Metalúrgica, de Materiais e de Minas, 21 a 25 de julho de 2014, São Paulo, SP, Brasil.
} 

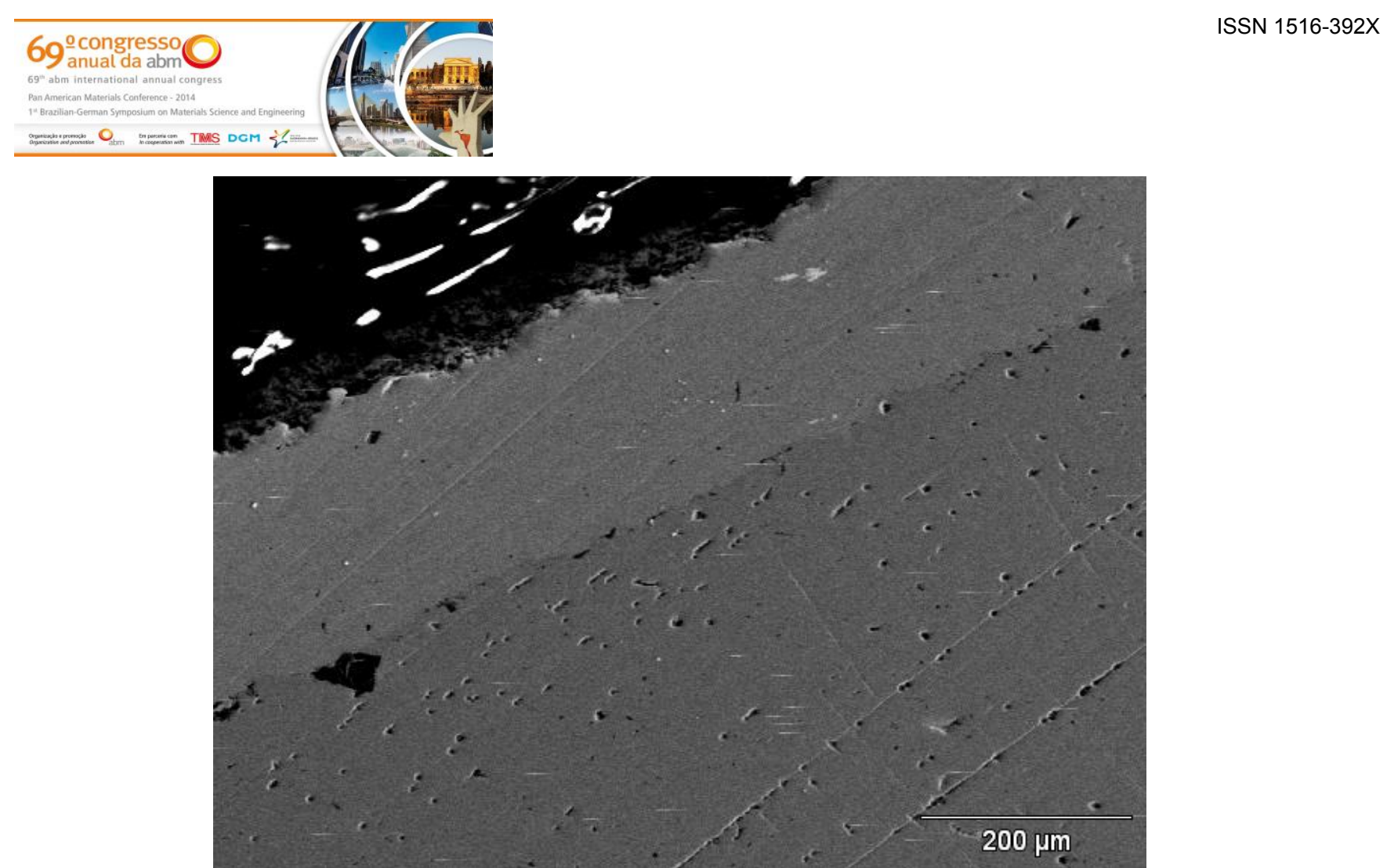

Figura 10. Imagem transversal do revestimento de níquel obtida por microscopia eletrônica de varredura.

Desta maneira, pode-se afirmar que mesmo o revestimento níquel apresentando poros superficiais, parece não haver poros passantes que atinjam o substrato, pelo menos na região observada.

\subsection{Ensaios Eletroquímicos}

Foram realizados curvas de polarização potenciodinâmica, como mostra a Figura 11. Destas curvas, foram extraídas os valores de potencial de corrosão (Ecorr), de densidade de corrente de corrosão (icorr) e de resistência de polarização (Rp) obtidos a partir da simulação por extrapolação das retas de Tafel.

O aço jateado apresentou maiores densidade de corrente de corrosão (icorr) e, portanto, os menores valores de resistência à polarização $(R p)$, além de apresentar valores mais ativos de potencial dentre todos os sistemas estudados, conforme Tabela 4. Já com o revestimento de níquel, os resultados apresentaram grandes melhoras no comportamento frente a corrosão, promovendo grandes aumentos na Rp e com valores de icorr muito inferiores ao aço jateado. Com isso, nota-se que o revestimento de níquel aplicado por aspersão térmica HVOF pode ser uma excelente opção de revestimento contra a corrosão para o aço API 5CT P110.

Estes valores mostram, também, que o revestimento de níquel por aspersão térmica neste substrato não apresentou passivação tão intensa e característica quanto o níquel puro, como poderia ser esperado. Esta razão pode estar associada à presença de irregularidades no revestimento, como os poros superficiais anteriormente relatados na figura 9 , bem como a presença de óxidos e outros contaminantes que são característicos do processo.

Entretanto, pode-se afirmar que os parâmetros de aspersão, utilizados neste trabalho conseguiram levar a obtenção de revestimentos com baixa porosidade e com a presença de poros não passantes e poucas irregularidades, o que foi decisivo para o bom desempenho frente à corrosão desses revestimentos.

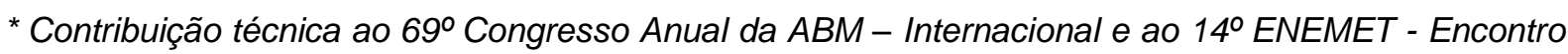
Nacional de Estudantes de Engenharia Metalúrgica, de Materiais e de Minas, 21 a 25 de julho de 2014, São Paulo, SP, Brasil.
} 

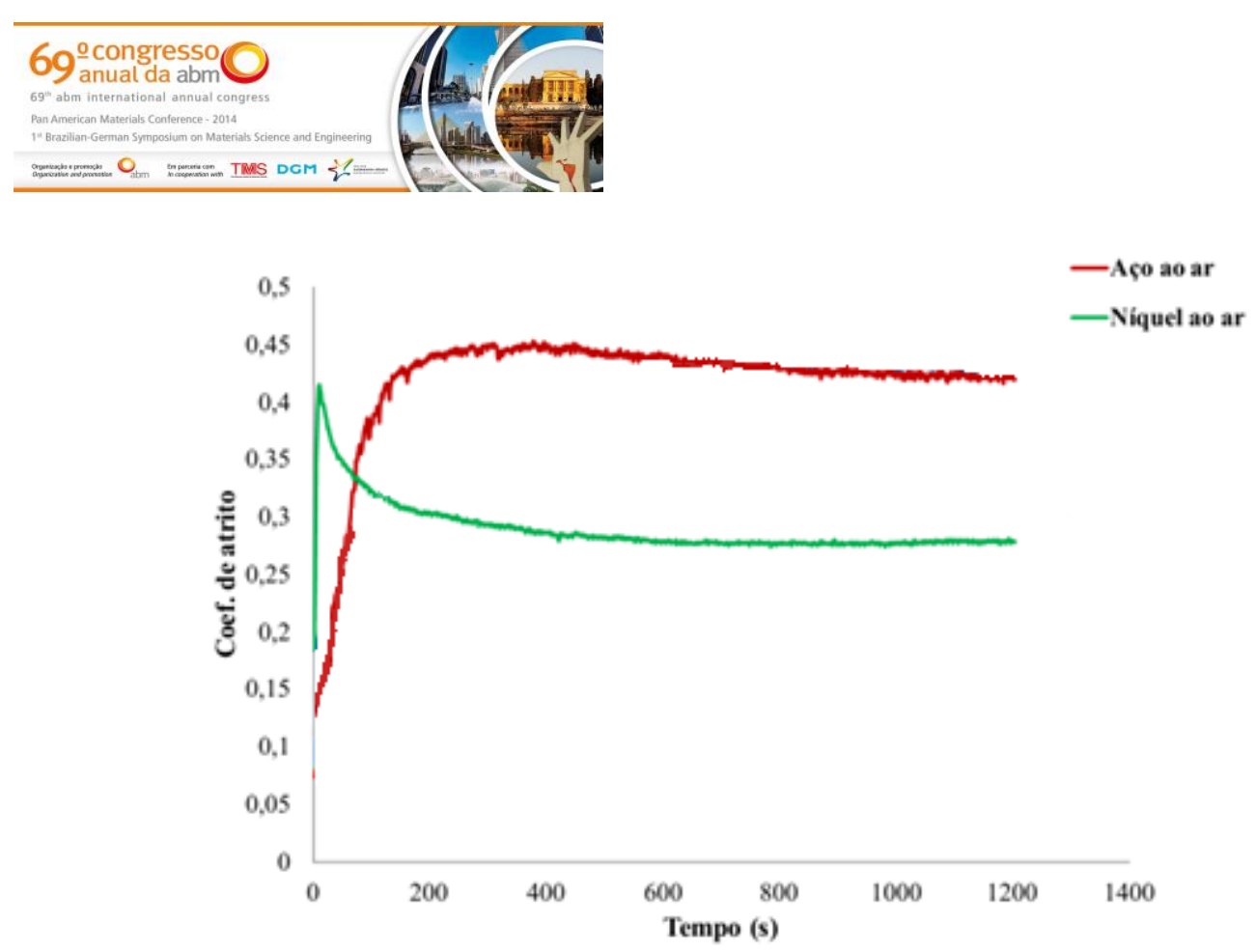

Figura 12. Gráfico de coeficiente de atrito pelo tempo obtidas no ensaio de determinação do coeficiente de atrito.

\section{CONCLUSÃO}

Frente aos resultados obtidos, após os ensaios realizados e devido aos parâmetros de aspersão empregados no processo, pode-se concluir que o revestimento de níquel sobre o substrato de aço API 5CT P110 apresentou-se morfologicamente bem constituído pois mostrou-se satisfatoriamente homogêneo, sem a presença de defeitos, como trincas e/ou micro trincas, e com baixos valores de porosidade.

Frente a corrosão, o revestimento se mostrou eficiente, já que apresentou valores de icorr cerca de 100x menores que o aço puro, além dos valores de potencial de corrosão que foram muito menos ativos que os potenciais de corrosão do substrato. Isso pode estar associado com a qualidade do revestimento e com a escolha do níquel, já que ele possui maior resistência intrínseca à corrosão, proporcionando grandes melhoras no desempenho a corrosão do substrato.

Quanto aos valores de coeficiente de atrito, nota-se que o revestimento de níquel diminui o coeficiente de atrito do substrato.

A camada aspergida de níquel apresentou resultados satisfatórios quanto às análises estudadas nesse trabalho, mostrando possuir um futuro promissor para sua aplicação em componentes da indústria do petróleo, principalmente no que tange a resistência à corrosão conferida ao substrato.

\section{Agradecimentos}

À Rijeza Indústria Metalúrgica LTDA, à Secretaria de Ciência, Inovação e Desenvolvimento Tecnólogo/ RS e ao CNPq pelo apoio financeiro.

\footnotetext{
* Contribuição técnica ao 69ำ Congresso Anual da ABM - Internacional e ao 14ํㅡㄹ ENEMET - Encontro Nacional de Estudantes de Engenharia Metalúrgica, de Materiais e de Minas, 21 a 25 de julho de 2014, São Paulo, SP, Brasil.
} 


\section{REFERÊNCIAS}

1 API (American Petroleum Institute). API Specification for Casing and Tubing / ISSO 11960: Petroleum and Natural Gás Indústries - Steel pipes for use as casing or tubing for wells. Washington, 2005.

2 Totten GE. Steel Heat Treatment: Metalurgy and Technologies. 2. Ed. Portland: Oregon, 2006.

3 ASM International - Metals Handbook - vol 7 - Power Metals Technologies and Applications. ASM Int., 1992.

4 Marques PV. Aspersão térmica. Infosolda e Universidade Federal de Minas Gerais, 2003.

5 Paredes RSC. Apostila de Aspersão Térmica, Universidade Federal Do Paraná. Curitiba. 2009.

6 Stokes J. The Theory and Application of the HVOF (High Velocity Oxy-Fuel). Disponível em:

http://webpages.dcu.ie/ stokesjt/ThermalSpraying/Book/HVOFThermalSpraying.htm, acessado em set/2011.

7 Pawlowski L. The Science and Engineering of Thermal Spray Coatings. John Wiley\& Sons, Ltd. 2008.

* Contribuição técnica ao 69 Congresso Anual da ABM - Internacional e ao 14ํㅡㄹ ENEMET - Encontro Nacional de Estudantes de Engenharia Metalúrgica, de Materiais e de Minas, 21 a 25 de julho de 2014, São Paulo, SP, Brasil. 